Research Article

\title{
Service Life Prediction of Shaft Sidewall Exposed to Sulfate Environment
}

\author{
Wei He $\mathbb{D}^{1},{ }^{1}$ Xia Meng $\mathbb{D}^{1},{ }^{2}$ and Ji-hui Zhao $\mathbb{i}^{3}$ \\ ${ }^{1}$ Department of Civil Engineering, Tsinghua University, Beijing 100084, China \\ ${ }^{2}$ Architectural Design and Research Institute of Tsinghua University Co., Ltd., Beijing 100084, China \\ ${ }^{3}$ School of Civil Engineering, Sun Yat-sen University, Guangzhou 510006, China
}

Correspondence should be addressed to Ji-hui Zhao; zhaojihui324@163.com

Received 18 February 2018; Revised 16 May 2018; Accepted 6 June 2018; Published 3 July 2018

Academic Editor: Yuanshi Li

Copyright ( $(2018$ Wei He et al. This is an open access article distributed under the Creative Commons Attribution License, which permits unrestricted use, distribution, and reproduction in any medium, provided the original work is properly cited.

\begin{abstract}
Under the influence of underground water with high concentration of sulfate, several vertical shafts in the Huang-Huai region are seriously corroded but have varying degradation degrees in different parts. Taking the auxiliary shaft of Lin-Huan coal mine as the research subject, the mechanism of this phenomenon was studied. Then, wet-dry alternated and immersion corrosion tests were carried out, and it was found that only the dry-wet alternated accelerate test is representative of the corrosion mechanism that cause the corrosion in the shaft. However, it will cost much time and money for the laboratory test to reach the same degradation depth. To solve this problem, combining with field and laboratory tests, a modified theoretical degradation model was developed to evaluate the residual life of the corroded sidewall. The results indicate that the residual life of the shaft sidewall is 25 years, and the damaged parts have no need for an immediate reinforcement.
\end{abstract}

\section{Introduction}

As the only passage way for transporting workers and equipment, the auxiliary shaft is extremely important to a coal mine, and its designed service life is usually more than 50 years. However, the service performance of shaft lining is degenerated by aggressive groundwater, microorganisms, and other environmental factors $[1,2]$. Due to limited coal reserves in a coal mine, there is no need for reinforcement if the corroded shaft sidewall has the ability to service safely until exhausted.

Methods that have been used for predicting the service life of an in-service structure generally include predictions based on experience, deductions from a similar structure exposing a similar environment, accelerated testing results, mathematical models based on sulfate ions transportation, and chemical reaction in the corrosion processes [3]. Prediction based on experience is a semiquantitative method; it is built on the accumulated knowledge from laboratory and field testing experience [4]. Because of the variability in materials, geometry, construction practices, and exposure to loads and environments, each structure has certain uniqueness. Thus, deductions from performance of similar structure have not been commonly used [5].

The damage of concrete under sulfate attack proceeds from the surface of concrete, the degradation depth is most suitable to represent the degradation degree of the corroded structure. But the specimens in the laboratory are much smaller than the in-service structure; thus, the degradation depth that makes the in-service structure unstable is very difficult to be achieved by the laboratory test. Several mathematic models [6-8] have been built to predict the degradation depth. But as mathematical models have uncertainties related to the model as well as the material and environmental parameters, prediction based on accelerated tests is used more widely [9-11].

The vertical shafts of coal mines are usually at great depths, and unavoidable contact some coal measure strata, which contain lots of corrosive ions. In Lin-Huan coal mine, the auxiliary shaft has varying degradation degrees in different parts. The part with aggressive water flow on is protected by a dense layer and is barely corroded. On the contrary, the moist part near the construction joint is seriously corroded. 


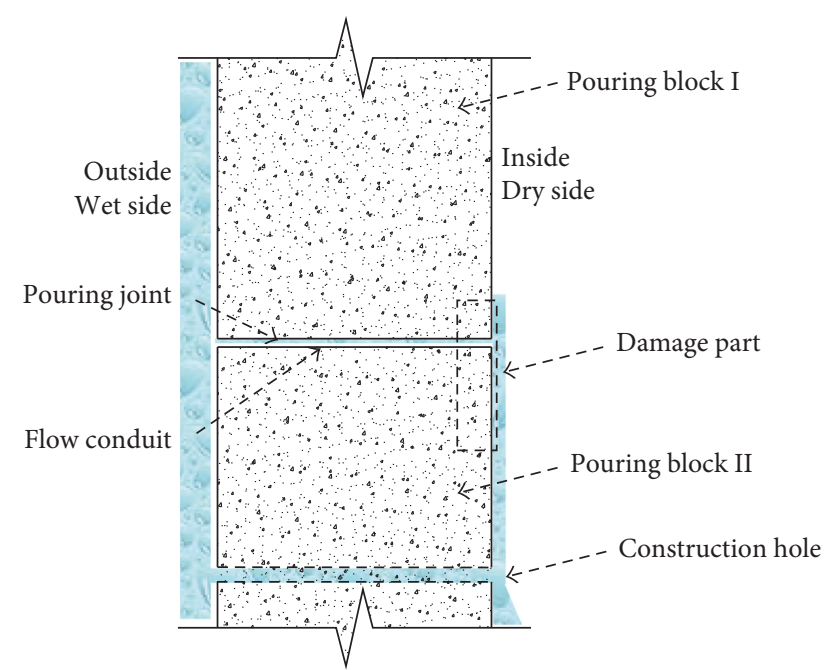

FIgURE 1: A schematic sketch of the field investigation.

TABle 1: Chemical composition of seepage water (mg/L).

\begin{tabular}{lccccccc}
\hline Number & $\mathrm{Na}^{+}$ & $\mathrm{Mg}^{2+}$ & $\mathrm{Ca}^{2+}$ & $\mathrm{CO}_{3}{ }^{2-}$ & $\mathrm{Cl}^{-}$ & $\mathrm{SO}_{4}{ }^{2-}$ & $\mathrm{pH}$ \\
\hline 1 & 362.1 & 160.6 & 378.9 & 95.8 & 236.9 & 1748.0 & 7.60 \\
2 & 556.4 & 111.7 & 291.7 & 69.9 & 181.7 & 1860.2 & 7.54 \\
3 & 626.6 & 101.8 & 227.7 & 91.7 & 176.7 & 1867.5 & 7.85 \\
Average & 515.0 & 124.7 & 299.4 & 85.8 & 198.4 & 1825.2 & 7.67 \\
\hline
\end{tabular}

Since this phenomenon has not been fully studied before, the remaining life is hard to evaluate by ordinary methods.

\section{Field Investigations}

The auxiliary shaft is one of the four vertical shafts in Lin-Huan coal mine. Its inner diameter is $7.2 \mathrm{~m}$. The sidewall in surface soil is made of $1.35 \mathrm{~m}$ thick double-layer reinforced concrete. The sidewall in bedrock is made of $0.5 \mathrm{~m}$ thick C30 plain concrete; the subsection pouring method was adopted. Given the unavoidable placing intermission, the bond between pouring blocks is weak, and a flow conduit had formed. The inner wall near the construction joint is moist but has no obvious flowing water, as shown in Figure 1. Several construction holes were drilled at the project acceptance stage, and the flow rate from each construction hole is usually more than $1.5 \mathrm{~L} / \mathrm{min}$.

2.1. Composition Analysis of the Aggressive Water. There are three major damaged parts in the auxiliary shaft, located at $-250 \mathrm{~m},-271 \mathrm{~m}$, and $-280 \mathrm{~m}$. Because of the low flow rate, water was difficult to collect at the construction joints. Thus, water from nearby construction holes was extracted for analysis. The water samples were analyzed by using an ICS5000 ion chromatographer. The results are presented in Table 1.

As the outer wall is soaked in underground water and the inner wall is exposed to the atmosphere, the environment effect can be classified as Class I [12]. Under Class I environment, when the content of $\mathrm{SO}_{4}{ }^{2-}$ ion is more than $1500 \mathrm{mg} / \mathrm{L}$, the sulfate effect is classified as "Very Strong."

The solubility product constant $K_{\mathrm{sp}}$ is the product of the equilibrium molar concentrations of the ions in a saturated solution of a salt in water. When the ion product $K$ of a salt is higher than the solubility product constant $K_{\mathrm{sp}}$, it is supersaturated. In the water samples, the average ion product $K$ of gypsum is $1.42 \times 10^{-4}$, and it is obviously higher than the solubility product constant $K_{\mathrm{sp}}\left(3.36 \times 10^{-9}\right.$ at $\left.25^{\circ} \mathrm{C}\right)$.

2.2. Chemical Composition Analysis. The most seriously damaged part is located at $-271.0 \mathrm{~m}$. At this part, the concrete of the sidewall is obviously bulging and the surface is very loose. As shown in Figure 2, the damaged layer is along the construction joint and is approximately $200 \mathrm{~mm}$ in height and $55 \mathrm{~mm}$ in depth. As shown in Figure 3, under the dense layer, the concrete seems to be very compact. The rebound test indicated that the compressive strength of the concrete protected by the dense layer is $26.7 \mathrm{MPa}$; it is almost unaffected by corrosion.

Corroded concrete samples from the $-271 \mathrm{~m}$ damaged part and a dense layer sample form $-284 \mathrm{~m}$ were collected for testing. The phases of the samples were measured by $\mathrm{X}$-ray powder diffraction with $\mathrm{Cu} \mathrm{K} \alpha$ radiation on a Rigaku Ultima IV type X-ray powder diffractometer operating at $40 \mathrm{kV}$ and $40 \mathrm{~mA}$. An FEI Quanta 250 Environmental Scanning Electron Microscope (SEM) equipped with an EDAX Apollo $\mathrm{X}$ silicon drift detector energy-dispersive $\mathrm{X}$-ray spectrometer (EDS) was used to observe the microstructure of the corroded concrete and the dense layer.

Figure 4(a) shows that the corroded concrete mainly consists of gypsum $\left(\mathrm{CaSO}_{4} \cdot 2 \mathrm{H}_{2} \mathrm{O}\right)$, quartz $\left(\mathrm{SiO}_{2}\right)$, albite $\left(\mathrm{NaAlSi}_{3} \mathrm{O}_{8}\right)$, margarite $\left(\mathrm{CaAl}_{2}\left(\mathrm{Al}_{2} \mathrm{Si}_{2}\right) \mathrm{O}_{10}(\mathrm{OH})_{2}\right)$, and calcite $\left(\mathrm{CaCO}_{3}\right)$. The diffraction peak of portlandite $\left(\mathrm{Ca}(\mathrm{OH})_{2}\right)$, which is one of the major components of normal concrete, was not found. However, gypsum, which is barely contained in normal concrete, is one of the major components. The average concentration of the sulfate ion and $\mathrm{pH}$ value in the water samples are 7.67 and $1825.2 \mathrm{mg} / \mathrm{L}$, respectively. According to Bellmann et al. [13], portlandite will react with gypsum at a minimal sulfate concentration of $1400 \mathrm{mg} / \mathrm{L}(\mathrm{pH}=14.5)$. With decreasing $\mathrm{pH}$, less concentration of sulfate ions is needed for the reaction to proceed. The reaction formula of this degradation is as follows:

$\mathrm{Ca}(\mathrm{OH})_{2}+\mathrm{SO}_{4}{ }^{2-}+2 \mathrm{H}_{2} \mathrm{O} \longrightarrow \mathrm{CaSO}_{4} \cdot 2 \mathrm{H}_{2} \mathrm{O}+2 \mathrm{OH}^{-}$

As can be seen from Figure 5, $\mathrm{Ca}^{2+}$ in calcium silicate hydrate (C-S-H) gel is partly replaced by $\mathrm{Mg}^{2+}$ to form hydrated magnesium silicate (M-S-H). Biczok [14] found that the corrosion process of concrete in magnesium sulfate usually included two steps: (1) C-S-H gel reacts with $\mathrm{SO}_{4}{ }^{2-}$ and $\mathrm{Mg}^{2+}$ to produce gypsum, magnesium hydroxide $(\mathrm{Mg}$ $\left.(\mathrm{OH})_{2}\right)$, silica gel, and $\mathrm{H}_{2} \mathrm{O} ;(2) \mathrm{Mg}^{2+}$ reacts with silica gel to form M-S-H and $\mathrm{H}_{2} \mathrm{O}$. The structure of $\mathrm{M}-\mathrm{S}-\mathrm{H}$ is much looser than C-S-H, and the adhesion between M-S-H and the aggregate is smaller. Thus, the deterioration degree of concrete in magnesium sulfate solution is much higher than in sodium sulfate solution [15]:

$$
\mathrm{Mg}^{2+}+\mathrm{C}-\mathrm{S}-\mathrm{H} \longrightarrow \mathrm{M}-\mathrm{S}-\mathrm{H}+\mathrm{Ca}^{2+}
$$

The sidewall in bedrock section was casted by section; therefore, the bond between pouring blocks is weak, and a hydraulic pathway is formed at the construction joint. 


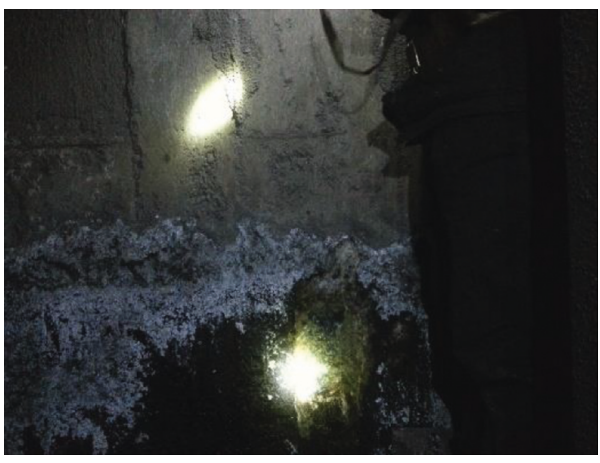

(a)

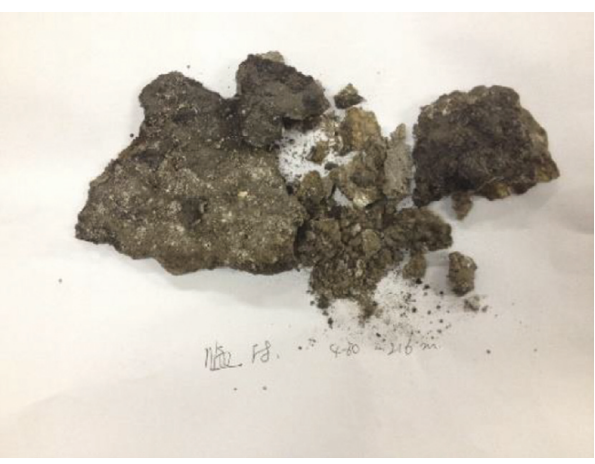

(b)

Figure 2: Corroded concrete (-271 m).

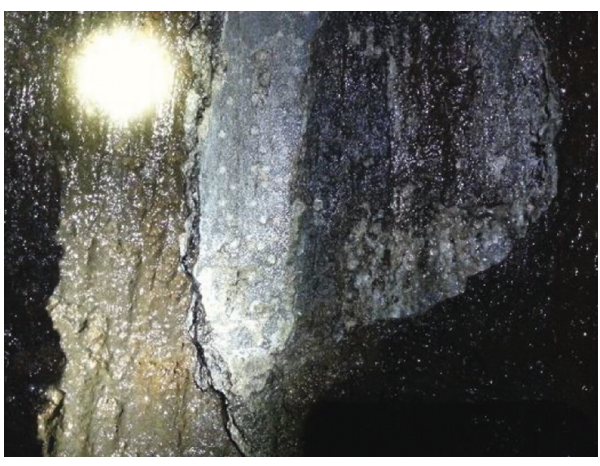

(a)

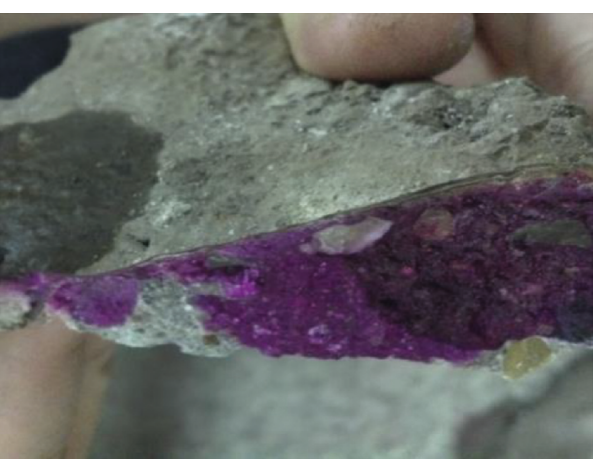

(b)

Figure 3: Compact concrete with a dense layer $(-284 \mathrm{~m})$.

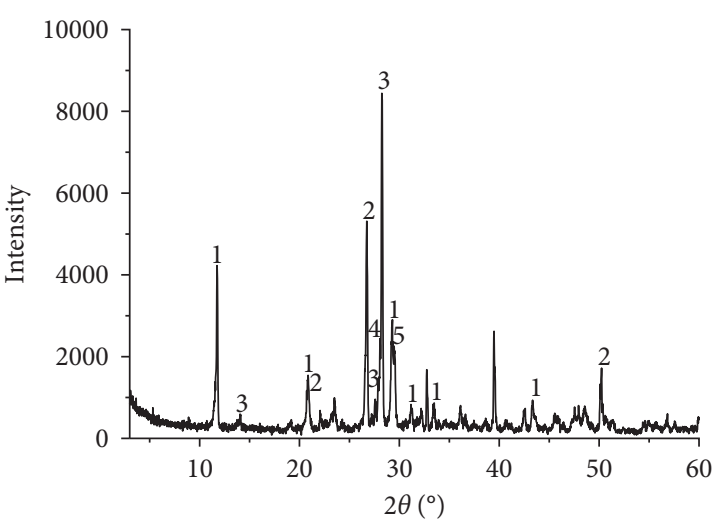

(a)

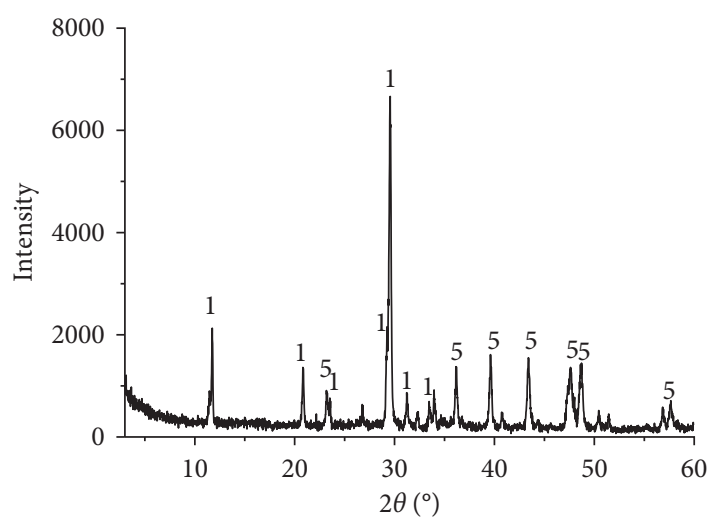

(b)

FIGURE 4: XRD analysis of the corroded concrete and the dense layer. (a) The corroded sidewall concrete; (b) the dense layer. 1: Gypsum; 2: quartz; 3: albite; 4: margarite; 5 calcite.

Because of a small flow of water and a mass of little cracks at the construction joint, the degeneration is aggravated by the internal crystallization of gypsum. As shown in Figure 3, the dense layer above the compact concrete is thin (less than $1-2 \mathrm{~mm}$ ), indicating that the gypsum from the supersaturated water is crystallized in very small amount. Thus, in the damaged part, it can only slightly accelerate the corrosion at the pouring joint and cannot be the main factor causing the degeneration.
As the diffraction peak of ordinary aggregates, such as quartz, albite, and margarite, was not found in Figure 4(b) and the major components of the dense layer are the same to the supersaturated salt in the aggressive water, the dense layer is supposed to be formed by the precipitation and crystallization from the supersaturated underground water. As shown in Figure 6, due to the compact microstructure of the dense layer, shaft concrete under the dense layer is barely corroded. 


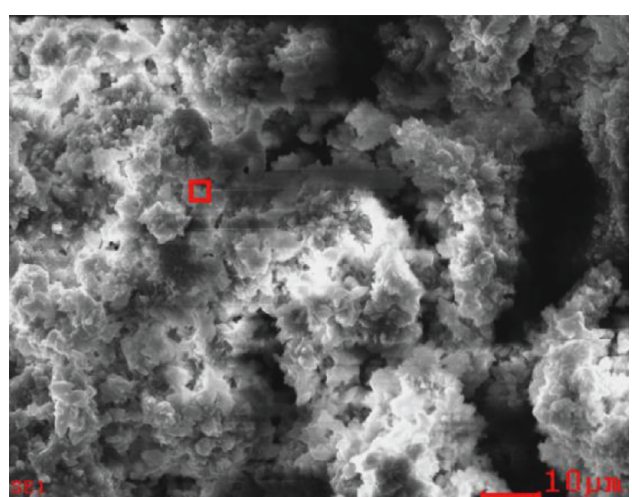

(a)

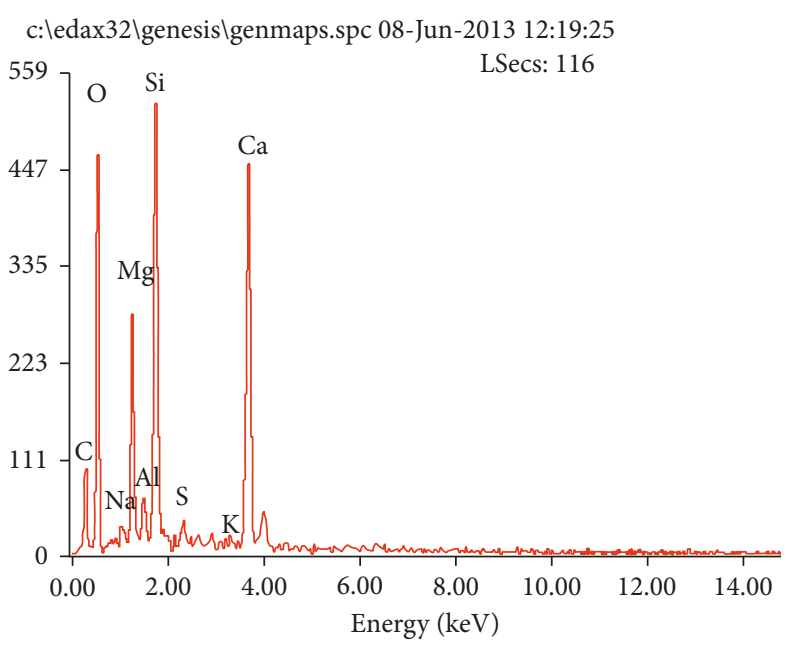

(b)

FIGURE 5: SEM and EDS images of the corroded concrete. (a) SEM; (b) EDS.

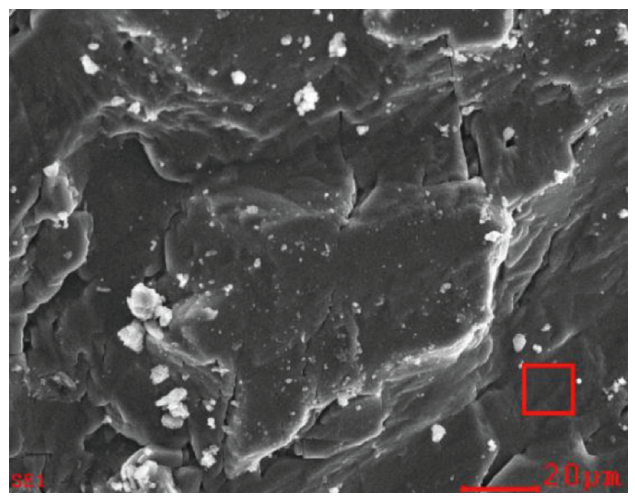

(a)

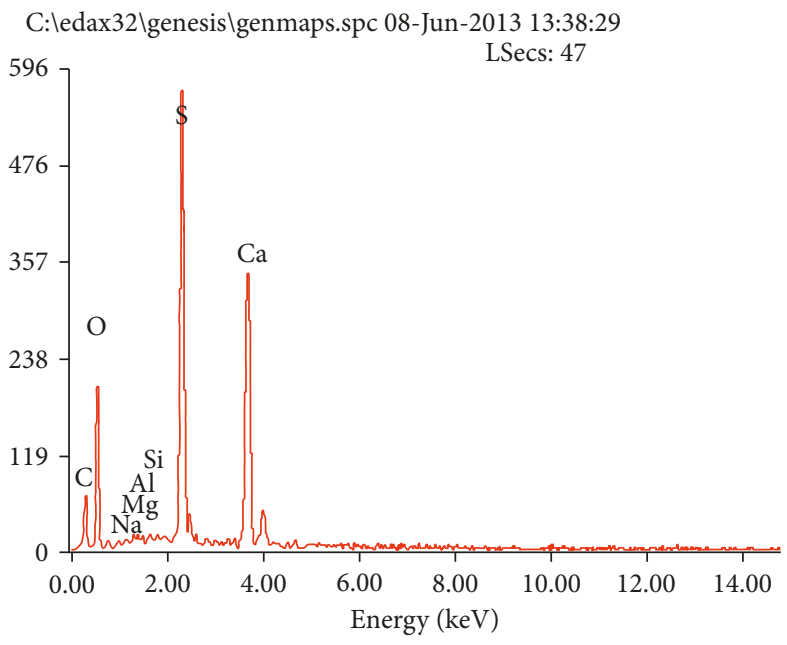

(b)

FIgURE 6: SEM and EDS images of the dense layer. (a) SEM; (b) EDS.

\section{Accelerated Corrosion Tests}

If the corrosion condition in the laboratory test is completely the same as that in field, the corroded in-service structure will lose carrying capacity before the specimen failure occurs in the laboratory. Therefore, for typical metal and nonmetallic materials, there are corresponding standard accelerated corrosion test methods, by artificially creating more severe conditions, to obtain the degeneration law in a short period of time.

\subsection{Experimental Procedure}

3.1.1. Materials and Specimen Preparation. Each pouring block needs to carry the gravity loads of the upper sidewall immediately after concrete mould is removed, so the $\mathrm{NaCl}$ $\mathrm{NaNO}_{3}$-TEOA compound component was used as an early strength agent. Table 2 shows the mix proportion of the C30 shaft concrete.
PO 42.5R Portland cement, continuous grading crushed stone in size of 5-20 mm, and river sand of fineness modulus of 2.8 were adopted. The major performance of the cement is shown in Table $3 . \mathrm{NaCl}, \mathrm{NaNO}_{3}$, and TEOA were analytically pure, produced by Sinopharm Group Co. Ltd. Drinking water supply was used in the preparation of the samples.

The specimens are $400 \times 100 \times 100 \mathrm{~mm}^{3}$ cuboids. A plastic board with $2 \mathrm{~mm}$ thickness, $100 \mathrm{~mm}$ width, and $40 \mathrm{~mm}$ height was used to create a notch in the middle of the specimens. The dimension of the concrete specimen is shown in Figure 7. The plastic board was removed in 6 hours. Form removal was carried out after 24 hours. Then, the specimens were cured at $20 \pm 2^{\circ} \mathrm{C}$ and $95 \%$ relative humidity until the age of 28 days.

3.1.2. Condition of the Accelerated Tests. Three accelerated corrosion tests were carried out including (1) immersion test with $9 \%$ sulfate solution; (2) immersion test with $15 \%$ sulfate solution; (3) wet-dry alternated test with $15 \%$ sulfate 
TABLE 2: Mix proportion of the shaft concrete $\left(\mathrm{kg} / \mathrm{m}^{3}\right)$.

\begin{tabular}{lccccccc}
\hline Material & Water & Cement & Sand & Rock & $\mathrm{NaCl}$ & $\mathrm{NaNO}_{3}$ & TEOA (triethanolamine) \\
\hline Weight & 176 & 400 & 620 & 1224 & 4 & 4 & 0.2 \\
\hline
\end{tabular}

TABLE 3: The major performance of the PO 42.5R cement.

\begin{tabular}{|c|c|c|c|c|c|c|c|}
\hline \multirow[t]{2}{*}{$80 \mu \mathrm{m}$ sieve residue } & \multirow[t]{2}{*}{ Water requirement } & \multirow[t]{2}{*}{ Initial setting time } & \multirow[t]{2}{*}{ Final setting time } & \multicolumn{2}{|c|}{$\begin{array}{l}\text { Flexural } \\
\text { strength }\end{array}$} & \multicolumn{2}{|c|}{$\begin{array}{l}\text { Compressive } \\
\text { strength }\end{array}$} \\
\hline & & & & $3 \mathrm{~d}$ & $28 \mathrm{~d}$ & $3 \mathrm{~d}$ & $28 \mathrm{~d}$ \\
\hline $0.6 \%$ & 0.268 & $180 \mathrm{~min}$ & $320 \mathrm{~min}$ & 3.5 & 7.5 & 25.2 & 48.4 \\
\hline
\end{tabular}
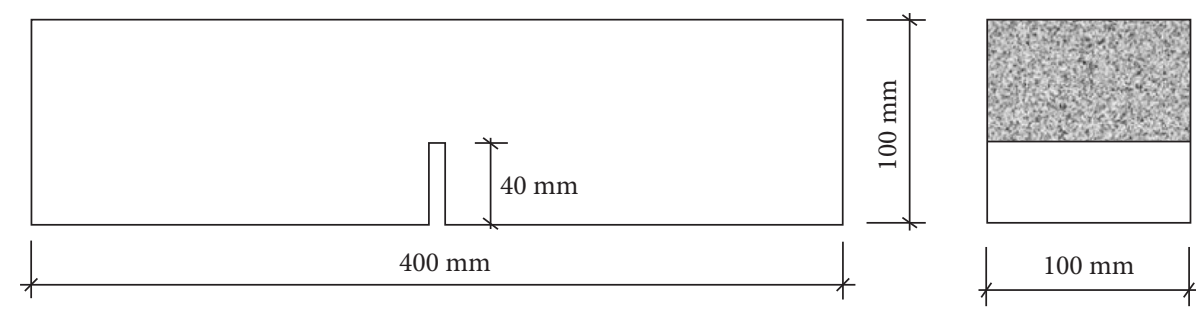

Figure 7: Size of the specimens.

TABLE 4: Grouping and testing arrangement.

\begin{tabular}{lcccccc}
\hline \multirow{2}{*}{ Group } & \multirow{2}{*}{ Corrosion condition } & \multicolumn{3}{c}{ Corrosion time (days) } & \multicolumn{3}{c}{ Content (by mass) } & 0 & 60 & 90 & 120 \\
\hline A & Immerged in sulfate solution & $9 \%$ & 3 & 3 & 3 & 3 \\
B & Immerged in sulfate solution & $15 \%$ & - & 3 & 3 & 3 \\
C & Wet-dry alternated & $15 \%$ & - & 3 & 3 & 3 \\
\hline
\end{tabular}

solution. In the immersion tests, the specimens were fully immersed in a sulfate solution. In the wet-dry alternated test, the NELD-LSC automatic sulfate dry-wet cycle testing machine was adopted. Each dry-wet cycle includes soaking in water for $16 \mathrm{~h}$, drying at $80^{\circ} \mathrm{C}$ for $6 \mathrm{~h}$, and cooling at room temperature for $2 \mathrm{~h}$. Sulfate solutions were made by mixing sodium sulfate $\left(\mathrm{Na}_{2} \mathrm{SO}_{4}\right)$ and magnesium sulfate $\left(\mathrm{MgSO}_{4}\right)$. The mass ratio of sodium sulfate and magnesium sulfate is $4: 1$. The sulfate solution was replaced every 30 days to maintain full immersion and to ensure that the sulfate concentration was maintained.

3.1.3. Characterization. The grouping and testing arrangements are shown in Table 4. At each testing age, three specimens from each group were taken out for ultrasonic tests first, and then three-point bending tests were conducted. The surface of the broken samples was mechanically crushed and ground into a powder of about 300-mesh size. XRD measurements were performed on a Rigaku Ultima IV type X-ray powder diffractometer. Then, the external small pieces of the crushed samples were analyzed by using SEM and EDS.

In the three-point bending test, fracture strength testing machine manufactured by Toni Technik Co., Ltd., JM3840 dynamic and static collect system manufactured by Jing Ming Technology Co., Ltd., and YYJ-5/10 electronic extensometer manufactured by NCS Testing Technology Co., Ltd. were adopted. The load speed of loading was controlled by displacement $(0.05 \mathrm{~mm} / \mathrm{min})$. Five strain gauges were placed on one side of the specimen to monitor the process of crack initiation, as shown in Figure 8.

Based on linear elastic fracture mechanics, $\mathrm{Xu}$ and $\mathrm{Zhao}$ [16] proposed a double-K fracture model, which has received the recommendation of China Electricity Council [17]. In double-K fracture model, two fracture parameters (initial fracture toughness $K_{\text {IC }}^{\mathrm{Q}}$ and unstable fracture toughness $K_{\text {IC }}^{\mathrm{S}}$ ) were defined to capture the three stages of the fracture process in concrete. The initial fracture toughness $K_{\mathrm{IC}}^{\mathrm{Q}}$ is defined as the ability of a body to resist an external load before the appearance of crack propagation and the unstable fracture toughness. $K_{\mathrm{IC}}^{\mathrm{Q}}$ is defined as the ability to resist a maximum external load at critical fracture condition [18]. The unstable fracture toughness $K_{\text {IC }}^{\mathrm{S}}$ and the elastic modules $E$ of the concrete specimens could be calculated as follows:

$$
K_{\mathrm{IC}}^{\mathrm{S}}=\frac{1.5\left(P_{\max }+(m g / 2) \times 10^{-2}\right) \times 10^{-3} \cdot S \cdot a_{\mathrm{c}}^{1 / 2}}{t h^{2}} f(\alpha),
$$

$$
\begin{aligned}
f(\alpha) & =\frac{1.99-\alpha(1-\alpha)\left(2.15-3.93 \alpha+2.7 \alpha^{2}\right)}{(1+2 \alpha)(1-\alpha)^{1.5}}, \\
\alpha & =\frac{a_{c}}{h}
\end{aligned}
$$




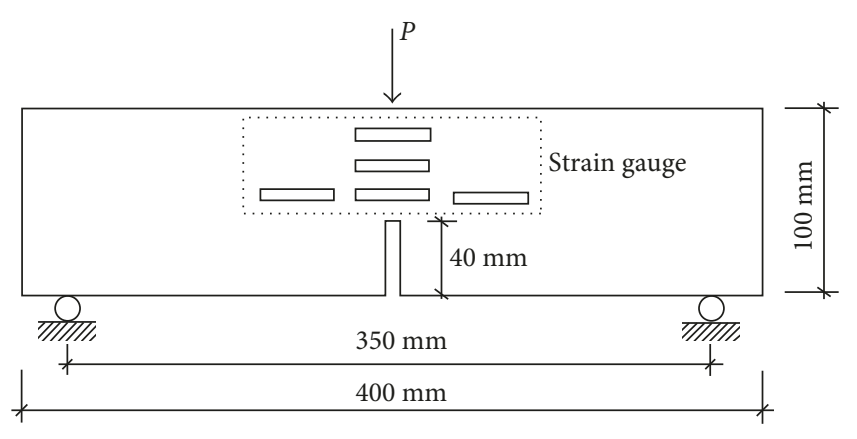

(a)

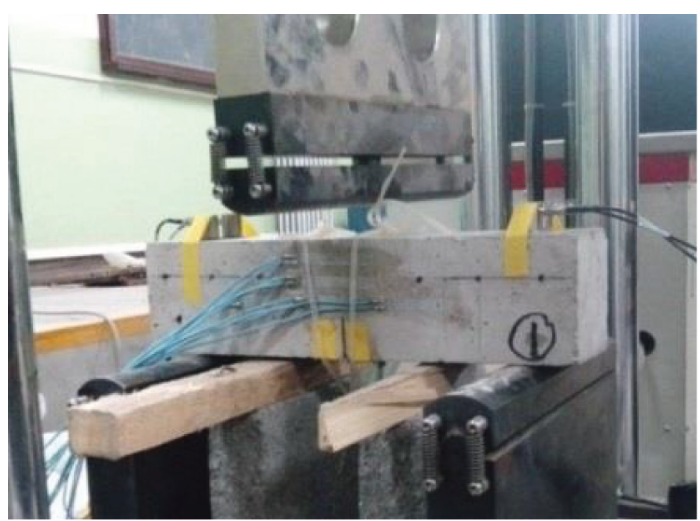

(b)

FIGURE 8: Schematic diagram of the three-point bending test.

Ultrasonic transducers

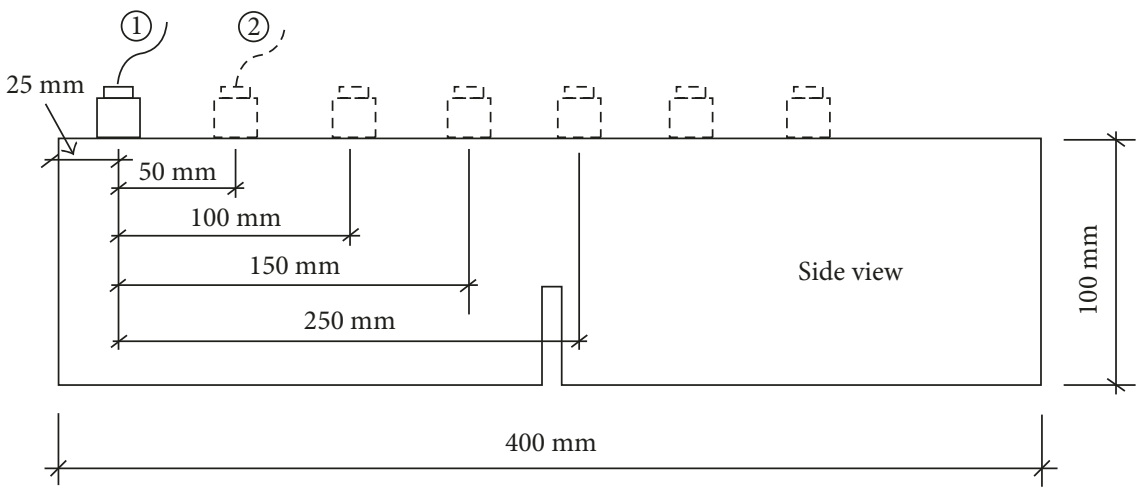

Figure 9: Diagram of the ultrasonic single side test method.

$$
\begin{aligned}
& a_{\mathrm{c}}=\frac{2}{\pi}\left(h+h_{0}\right) \arctan \left(\frac{t E \mathrm{CMOD}_{\mathrm{c}}}{32.6 P_{\max }}-0.1135\right)^{1 / 2}-h_{0}, \\
& E=\frac{1}{t c_{i}}\left[3.70+32.60 \tan ^{2}\left(\frac{\pi}{2} \frac{a_{0}+h_{0}}{h+h_{0}}\right)\right],
\end{aligned}
$$

where $P_{\max }$ is the maximum load, $\mathrm{kN} ; m$ is the weight of the specimen between the two supports, $\mathrm{kg} ; t$ and $h$ are the width and depth, respectively, of the specimen, $m ; a$ is the height to width ratio of the crack, constant; $a_{\mathrm{c}}$ is the maximum crack opening displacement, $m ; a_{0}$ is the length of the crack, $m ; h_{0}$ is the blade thickness of electronic extensometer, $m$; $C M O D_{c}$ is critical crack mouth opening displacement, $\mu \mathrm{m}$; and $c_{i}$ is the slope at any point of linear segment, $\mu \mathrm{m} / \mathrm{kN}$.

The NM-4B nonmetallic ultrasonic detector manufactured by Koncrete Co., Ltd. was adopted to obtain the degradation thickness of the specimens. The ultrasonic time is determined by the ultrasonic single side test method, as shown in Figure 9. One of the ultrasonic transducers was fixed at a certain position. When the other one was placed at $50,100,150,200$, and $250 \mathrm{~mm}$ away, and the corresponding ultrasonic time was recorded.

Then, the degradation depth can be calculated as follows [19]:

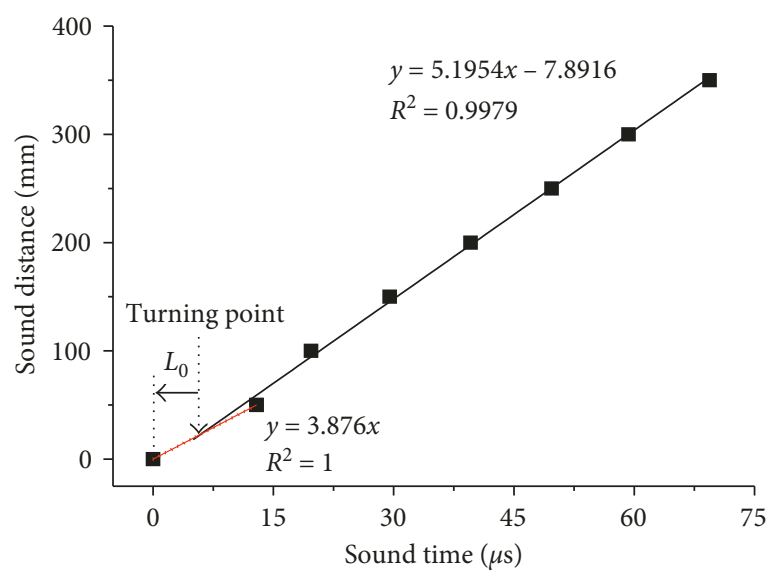

FIgURE 10: Calculation chart for $L_{0}$ (Group B, 60 days).

$$
d_{\mathrm{fc}}=\frac{L_{0}}{2} \sqrt{\frac{v_{\mathrm{a}}-v_{\mathrm{f}}}{v_{\mathrm{a}}+v_{\mathrm{f}}}},
$$

where $v_{\mathrm{f}}$ is the ultrasonic velocity in the corroded layer, $\mathrm{mm} / \mu \mathrm{m} ; v_{\mathrm{a}}$ is the ultrasonic velocity in the internal uncorroded concrete, $\mathrm{mm} / \mu \mathrm{m}$; and $L_{0}$ is the turning point in the "ultrasonic time-distance" diagram, mm. Figure 10 is an example. 


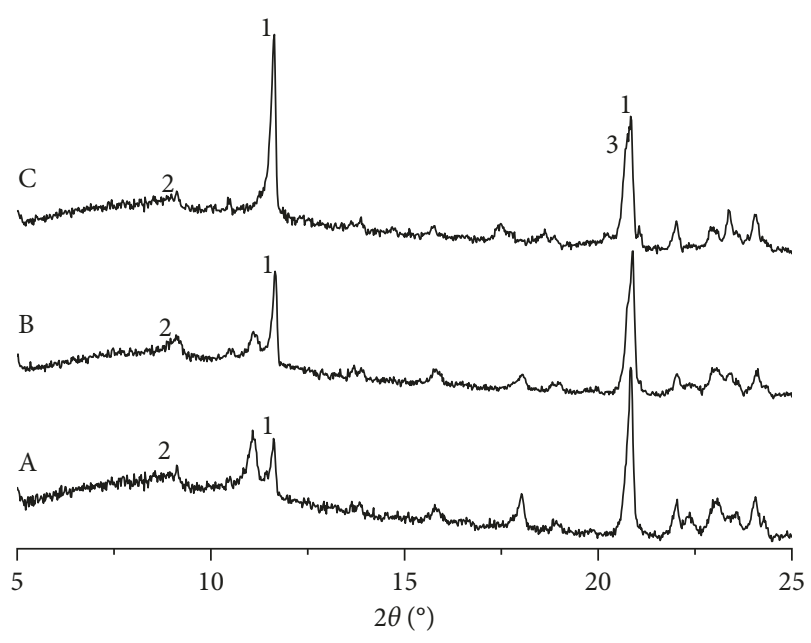

FIGURE 11: XRD results of corroded concrete (150 days). 1: Gypsum; 2: AFT; 3: quartz.

3.2. Corrosion Mechanism Analysis. Sulfate solution transports through the pore of concrete, resulting in chemical reactions between sulfate and cement hydration products. Expansive reaction products, such as ettringite and gypsum, generate high stress in the pore, causing spalling and cracking of the concrete. Some reaction products, such as $\mathrm{M}-\mathrm{S}-\mathrm{H}$ and magnesium hydroxide, are not expansive products, but are nonbinders. As concrete specimens with different corrosion mechanisms have different corrosion products and have different degeneration law, the degradation mechanism in the accelerated corrosion test should be the same as that responsible for the in-service deterioration [20]. XRD, SEM, and EDS analyses were performed on the corroded samples to analyze their corrosion mechanism, as shown in Figures 11 and 12.

As shown in Figure 11, the content of gypsum from high to low is Groups C, B, and A. A small amount of ettringite was found in Groups B and A. In the wet-dry alternated test, due to the adoration of sulfate solution in the pores during the "wet" process and the evaporation of the solution during the "dry" process, sulfate concentration in concrete pores is actually higher than that in the solution, which not only accelerates the corrosion rate of sulfate but also inhibits the occurrence of ettringite crystalline sulfate corrosion. But ettringite was not found in the field investigations. As can be seen from Figure 12, in the wet-dry alternated test, $\mathrm{Ca}^{2+}$ in C-S-H gel is also partly replaced by $\mathrm{Mg}^{2+}$ to form $\mathrm{M}-\mathrm{S}-\mathrm{H}$, which is similar to field corrosion. Thus, wet-dry alternated accelerated corrosion experiment is more representative to the field corrosion.

3.3. Performance Degradation in Different Accelerated Tests. As shown in Figure 13, the surfaces of the specimens immersed in $15 \%$ sulfate solution for 150 days are uneven and rough, the edges are slightly damaged, and some of the coarse aggregates are exposed. The specimen placed in the dry-wet cycle testing machine for 150 days is seriously corroded, especially at the edges, and the internal aggregates are exposed.

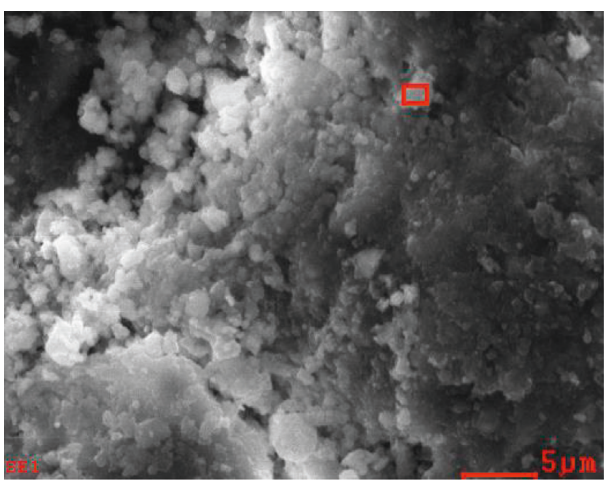

(a)

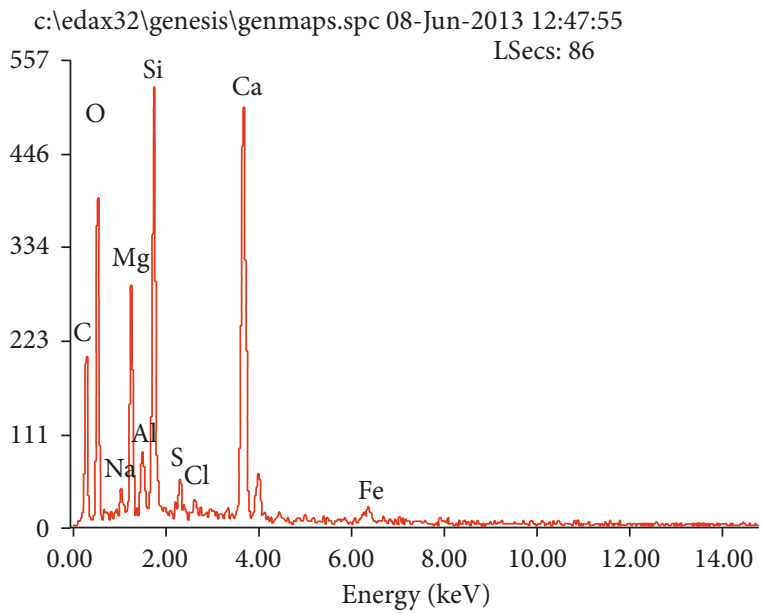

(b)

FIGURE 12: SEM and EDS images of the specimen in the wet-dry alternated test (150 days). (a) SEM (50,000x magnification); (b) EDS.

3.3.1. Degradation Depth. During the process of sulfate corrosion, a series of corrosion reactions occur, causing the concrete surface loose. If the ultrasonic wave encounters the defect regions, such as cracks and holes, the propagation path will increase, resulting in the increase of ultrasonic time and the decrease of calculated ultrasonic velocity. Thus, the calculated ultrasonic velocity can be used to reflect the degradation degree of the corroded specimen.

Figure 14(a) shows the surface ultrasonic velocity of the concrete specimens. As the corrosion time is increased, the surface ultrasonic velocity of Group C exhibits a decreasing trend and it is much lower compare to the results from Groups A and B. At the corrosion time of 150 days, the surface velocities of Groups A, B, and C are 3.82, 3.56, and $2.14 \mathrm{~km} / \mathrm{s}$, respectively, decreased by $21.6 \%, 26.9 \%$, and $43.9 \%$. It seems that the corrosion degree of the corrosion layer in the wet-dry alternated experiment is much more serious than that in immersion tests.

Figure 14(b) shows the degradation depth of the corroded specimens. In immersion tests, due to the filling of corrosion products in concrete pores, there is no obvious corrosion before 90 days. Then, the degradation depth increased steadily to the end the experiment. However, in the wet-dry alternated accelerated corrosion test, the degradation depth increased 


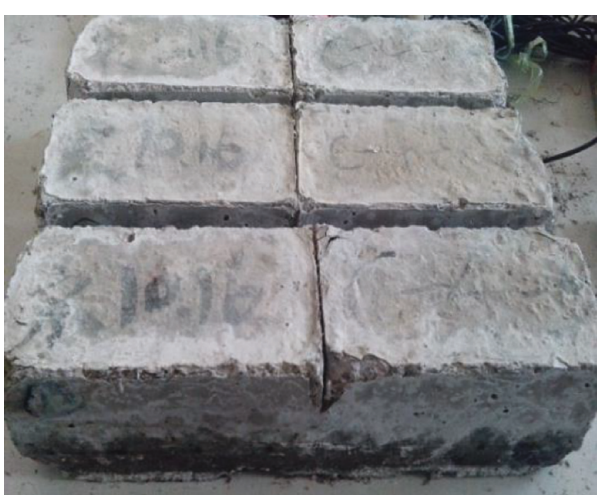

(a)

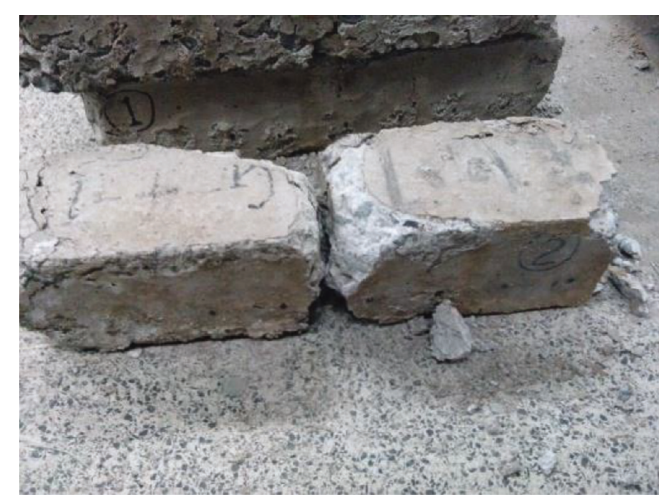

(b)

Figure 13: Appearances of the corroded specimens (150 days). (a) Immersion test (15\%); (b) wet-dry alternated test.

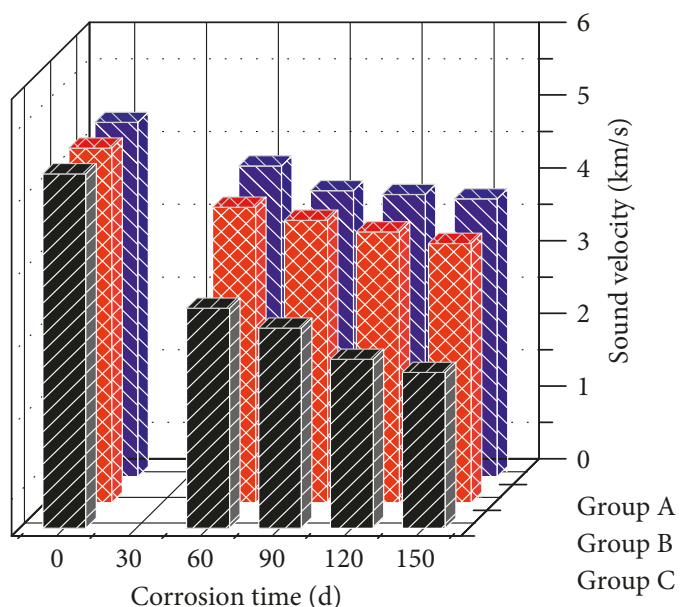

(a)

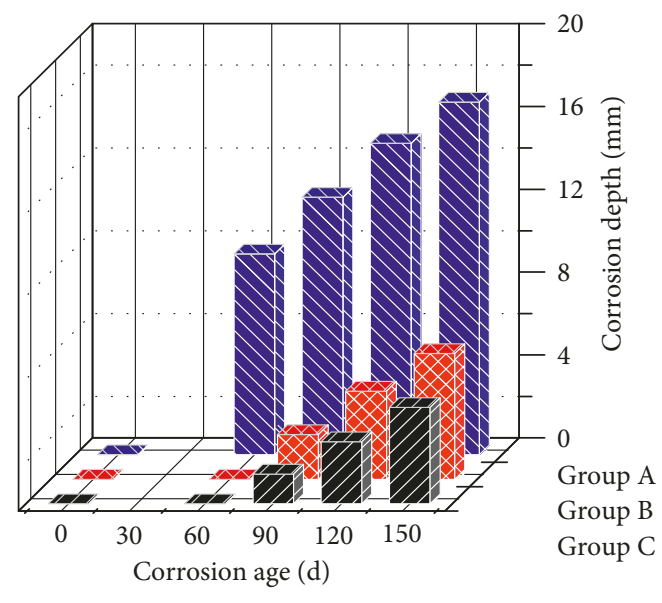

(b)

FIGURE 14: Surface ultrasonic velocity and degradation depth at different corrosion time. (a) Surface ultrasonic velocity; (b) degradation depth.

rapidly before 90 days. Then, with the corrosion time increasing, the growth started to flatten.

\subsubsection{Elastic Module and Unstable Fracture Toughness.} Figure 15 illustrates the results of elastic module $E$ and unstable fracture toughness $K_{\mathrm{IC}}^{\mathrm{S}}$ of corroded specimens at different corrosion time.

It can be seen from Figure 15(a) that, with corrosion time increasing, the elastic module of Group A and Group B increases at first and then gradually declines. Due to the high degradation rate, the elastic module of Group $\mathrm{C}$ has no increasing stage, and its decline speed is more rapid than Groups A and B. As shown in Figure 15(b), the unstable fracture toughness of Groups A, B, and C shows a similar decreasing trend during the early stages of corrosion. But after 90 days of corrosion, the decreasing trend of Group $\mathrm{C}$ is remarkable obvious, whereas, Groups A and B are slow.

\section{Service Life Prediction}

Damage of concrete under sulfate attack proceeds from the surface, thus the damage degree of a structure can be expressed as a function of the degradation depth [21]. The acceleration corrosion factor (ACF) is the ratio of service time to accelerated time corresponding to the same degradation depth [22]. Accelerated testing programs, if properly designed, performed, and interpreted, can help predict the performance and service life of concrete [20,23, 24].

As described in Section 2, for the wet-dry alternated accelerated test, not only the degradation rate is much faster than immersion test but also the degradation process is more similar to the field corrosion. However, due to limited specimen size and test condition, after 150 days of corrosion, the degradation depth in the wet-dry alternated test is just $17 \mathrm{~mm}$ and is much lower than the current corrosion depth of the sidewall $(55 \mathrm{~mm}$ at $-271 \mathrm{~m})$. It will take too much time and money in the laboratory to reach the same degradation depth that causes the failure of the sidewall. Therefore, combing with limited corrosion data, a modified theoretical model was applied to develop a long-run degradation depth function to estimate the residual life of the corroded sidewall.

The three major damaged parts are not far from one another, and the properties of nearby strata are similar. Thus, the computation of shaft sidewall reliability can be 


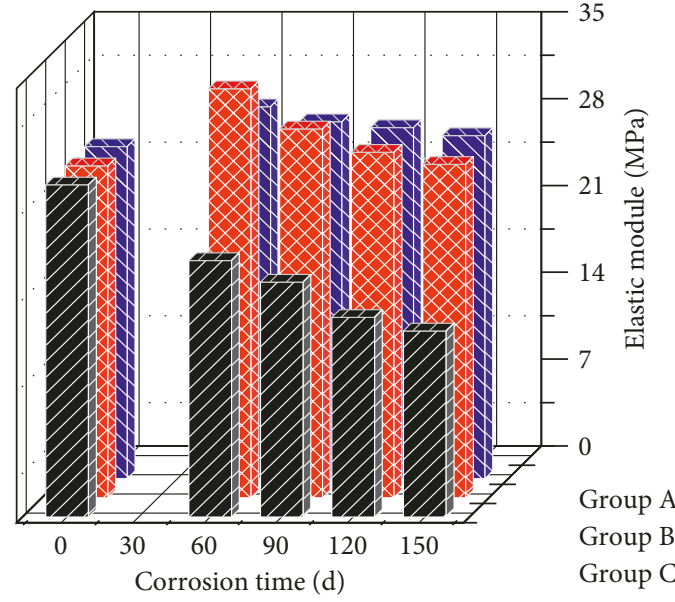

(a)

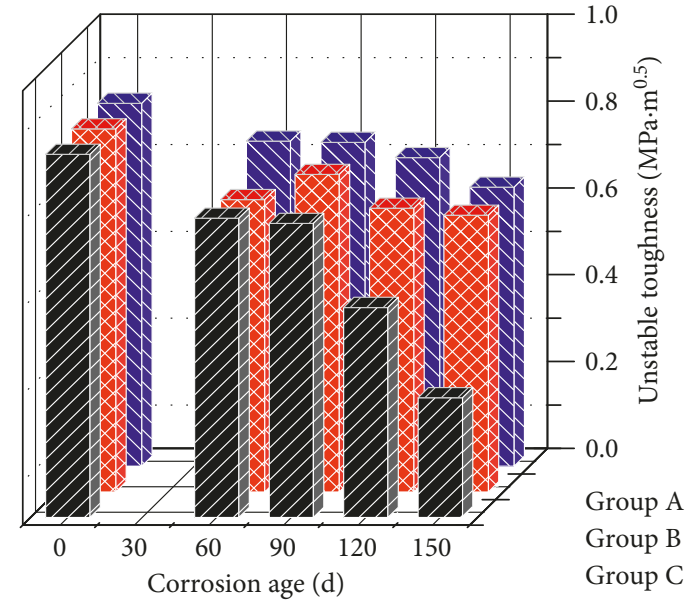

(b)

FiguRE 15: Elastic module and unstable fracture toughness at different corrosion time. (a) Elastic module; (b) unstable fracture toughness.

transferred to compute the most dangerous structure member reliability.

4.1. Degradation Depth Prediction Function. Based on Fick's law of diffusion, Li et al. [25] proposed a time-varying model to represent the degradation process:

$$
d_{0}=\sqrt{\frac{2 D C_{s} t}{n}}
$$

where $d_{0}$ is degradation depth, $\mathrm{mm}$; $D$ is diffusion coefficient of internal concrete, $\mathrm{mm}^{2} / \mathrm{d} ; C_{s}$ is concentration of sulfate at the surface of the concrete, $\mathrm{mol} / \mathrm{L}$; $t$ is corrosion time, $d$; and $n$ is sulfate absolute capacity, $\mathrm{mol} / \mathrm{L}$.

In a report from the US Bureau of Reclamation [24], the rate of the performance deterioration of concrete caused by the wet-dry alternated accelerated test was eight times that of the concrete caused by pure soaking. Zhou et al. [26] proposed that the acceleration effect of wet-dry cycles on the rate of sulfate diffusion can be simply equivalent to the amplification adjustment of the diffusion coefficient. Thus, we define $\eta$ as the coefficient of influence of wet-dry cycles on the diffusion coefficient of concrete. Substituting it in (7), it yields

$$
d_{0}=\sqrt{\frac{2 \eta D C_{\mathrm{s}} t}{n} .}
$$

Thus, the long-term degradation depth function of the wet-dry alternated tests is

$$
d_{0}=\sqrt{1.818 t} .
$$

The acceleration corrosion factor, ACF, which can be assumed to be a constant, can be obtained from [20]:

$$
\mathrm{ACF}=\frac{R_{\mathrm{AT}}}{R_{\mathrm{LT}}},
$$

where $R_{\mathrm{AT}}$ is the degradation rate of the specimens in accelerated tests, $\mathrm{mm} / \mathrm{d}$, and $R_{\mathrm{LT}}$ is the degradation rate of the in-service structure, $\mathrm{mm} / \mathrm{d}$.

As the shaft sidewall has been in-service for 26 years ( $9490 \mathrm{~d}$ ) and the degradation depth at $-271 \mathrm{~m}$ is $55 \mathrm{~mm}$, the ACF is 5.702 .
The relationship between the degradation depth of shaft sidewall $d_{\mathrm{c}}$ in $\mathrm{mm}$ and service time $T$ in days is as follows:

$$
d_{\mathrm{c}}=\sqrt{0.319 \mathrm{~T}} .
$$

4.2. Limit State Function of Shaft Sidewall. The external forces on the shaft sidewall mainly contain horizontal force $P_{\mathrm{h}}$ and vertical force $P_{\mathrm{v}}:(1) P_{\mathrm{h}}$ includes formation and water pressure, and (2) $P_{\mathrm{v}}$ includes the deadweight of the superstructure and additional force caused by soil settling [27].

The radial pressure on the outer shaft wall can be calculated with the following formula [28]:

$$
P=\sum_{i=1}^{n}\left(\gamma_{i} g h_{i}\right) A_{i},
$$

where $\gamma_{i}$ is the bulk density of $i$ th strata, $\mathrm{kg} / \mathrm{m}^{3} ; g$ is gravitational acceleration, $10 \mathrm{~N} / \mathrm{kg} ; h_{i}$ is the thickness of $i$ th strata, $m$; and $A_{i}$ is the lateral pressure coefficient of $i$ th strata.

According to $\mathrm{Ni}$ [29] and Zhang [30], the average bulk density and the lateral pressure coefficient can be assumed to be $2300 \mathrm{~kg} / \mathrm{m}^{3}$ and 0.164 , respectively. Thus, the lateral pressure on the sidewall at $-271 \mathrm{~m}$ is $1.06 \mathrm{MPa}$.

Compared with the gravity of the shaft sidewall, the equipment weight is very small and can be generally ignored. Bedrock is hard to be compressed, and the vertical pressure is as follows:

$$
P_{\mathrm{v}}=\gamma g H,
$$

where $\gamma$ is the bulk density of shaft sidewall, $\mathrm{kg} / \mathrm{m}^{3}$, and $H$ is the depth, $m$.

The average bulk density is assumed to be $2400 \mathrm{~kg} / \mathrm{m}^{3}$, thus the vertical pressure on the sidewall at $-271 \mathrm{~m}$ is $6.50 \mathrm{MPa}$.

Only when the ratio of vertical and horizontal stress, $P_{\mathrm{v}} / P_{\mathrm{h}}$, is greater than 10 , the failure of the shaft wall is dominated by the vertical stress [31]. As the $P_{\mathrm{v}} / P_{\mathrm{h}}$ is 6.13 , the performance function can be simplified to consist of horizontal resistance and horizontal load.

The cross section of the shaft wall is symmetrical in shape and forces, the relationship between radial force $\sigma_{\mathrm{r}}$ and 
circumferential force $\sigma_{\theta}$ can be described as $\left(d \sigma_{\mathrm{r}} / d r\right)+$ $\left(\sigma_{\mathrm{r}}-\sigma_{\theta} / r\right)=0$. Thus,

$$
\sigma_{\mathrm{r}}=\left(1-\frac{r_{1}}{r}\right) \sigma_{\theta}
$$

The sidewall concrete is reinforced by the confining pressure. According to lots of test data, the ultimate strength of the shaft sidewall can be described as follows [32]:

$$
\sigma_{\theta}-K \sigma_{\mathrm{r}}=f_{\mathrm{c}}
$$

where $f_{c}$ is the axial compressive strength of concrete, $\mathrm{MPa}$, and $K$ is strengthening coefficient. It can be calculated from the formula $K=0.8896 \lambda^{-1.2708} f_{c}^{0.2639}$ or chosen based on experience (2.2-3.0).

By substituting (17) in (16), the radial force $\sigma_{\mathrm{r}}$ can be calculated as follows:

$$
\sigma_{\mathrm{r}}=\frac{\left(1-\left(r_{1} / r\right)\right) f_{\mathrm{c}}}{1-\left(1-\left(r_{1} / r\right)\right) K}
$$

When the radial force reaches the ultimate bearing capacity of the shaft sidewall, the load-carrying resistance is

$$
R=\frac{\left(1-\left(r_{1} / r_{2}\right)\right) f_{\mathrm{c}}}{1-\left(1-\left(r_{1} / r_{2}\right)\right) K}
$$

where $r_{1}$ is the inner radius of the shaft sidewall, $\mathrm{m}$, and $r_{2}$ is the outer radius of the shaft sidewall, $\mathrm{m}$.

We assume that the strengthening coefficient $K$ is 2.5, and the limit state function can be calculated as follows:

$$
Z=\frac{f_{\mathrm{c}}\left(1-\left(r_{1}+d_{\mathrm{c}} / r_{2}\right)\right)}{1-2.5\left(1-\left(r_{1}+d_{\mathrm{c}} / r_{2}\right)\right)}-\gamma g h A,
$$

where $d_{\mathrm{c}}$ is the degradation depth, $\mathrm{mm}$.

4.3. Reliability Index of Corroded Sidewall. The limit state can been expanded using Taylor's series, and if only the first order terms are retained, if $X=\left[f_{c}, d_{c}, \gamma, A\right]^{T}$, we get

$$
Z=g(X) \approx g\left(\mu_{\mathrm{X}}\right)+\left(\frac{\partial g}{\partial X}\right)_{X=\mu_{\mathrm{X}}}^{T}\left(X-\mu_{\mathrm{X}}\right) .
$$

The variables $f_{\mathrm{c}}, d_{\mathrm{c}}, \gamma$, and $A$ can be assumed to be statistically independent, and then the mean and variance of $Z$ are then approximated by

$$
\begin{aligned}
\mu_{\mathrm{Z}} & =g\left(\mu_{f_{\mathrm{c}}}, \mu_{d_{\mathrm{c}}}, \mu_{\gamma}, \mu_{A}\right), \\
\sigma_{\mathrm{Z}} & =\left(b^{T} \sum_{\mathrm{X}} b\right)^{1 / 2}, \\
b & =\left(\frac{\partial g}{\partial X}\right)_{X=\mu_{\mathrm{X}}} .
\end{aligned}
$$

Then, the reliability index of the shaft sidewall at $-271 \mathrm{~m}$ is

$$
\beta=\frac{\mu_{\mathrm{Z}}}{\sigma_{\mathrm{Z}}} \text {. }
$$

The analysis of the reservation test block shows that the strength of the shaft concrete is distributed normally, the

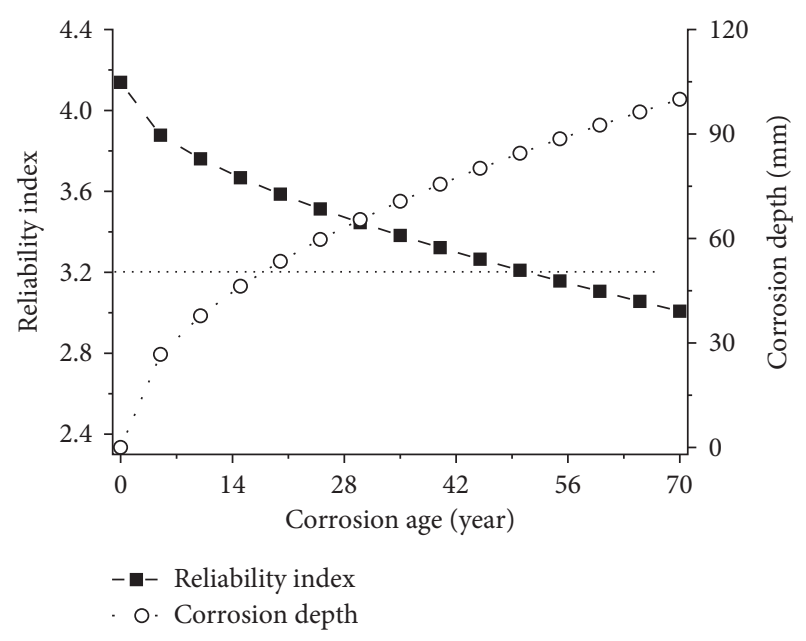

FIgURE 16: Reliability index and degradation depth at different service time.

TABLE 5: Target reliability index of bearing capacity limit state.

\begin{tabular}{lccc}
\hline Importance of structure & Class I & Class II & Class III \\
\hline Ductile failure & 3.7 & 3.2 & 2.7 \\
Brittle failure & 4.2 & 3.7 & 3.2 \\
\hline
\end{tabular}

average axial compressive strength is $17.00 \mathrm{MPa}$, and the variation coefficient is 0.1374 [33]. The variation coefficient of the degradation depth is assumed to be 0.1 [34]. The mean values of the lateral pressure coefficient and bulk density are 0.164 and $2300 \mathrm{~kg} / \mathrm{m}^{3}$, respectively. As the geotechnical mechanics parameters are hard to calculate accurately [35], the variation coefficients of the lateral pressure coefficient and bulk density are assumed to be 0.20 and 0.15 , respectively.

After calculation, the reliability indexes and degradation depths at different corrosion time are shown in Figure 16. The target reliability index of bearing capacity limited state, which is recommended by MOHURD (Ministry of Housing and Urban-Rural Development of the People's Republic of China), is shown in Table 5 [36].

The sidewall is subjected to a multidirectional pressure, so the failure mode of the shaft sidewall can be assumed to be ductile failure. The auxiliary shaft undergoes a routine check on a daily basis, and the failure risk can be identified with a timely fashion. As the lives of thousands of workers depend on it, the target reliability is set as 3.2. At present, the service time of the shaft sidewall is 26 years, and the reliability index is 3.50. It is safe now, but with the service time increasing, the reliability index will unavoidably decrease. When the reliability index reduces to 3.20 , the service time will be 51 years. It is obvious that there is no need to reinforce in the next 25 years.

\section{Conclusions}

(1) In the aggressive underground water of Lin-Huan coal mine, gypsum is supersaturated. When the aggressive water flows on the compact concrete, a dense layer formed by the crystallized precipitations protects it 
against sulfate attack. By contrast, the degradation of the part where water flows through pouring joints is aggravated by the internal crystallization of gypsum.

(2) Apart from the internal crystallization of gypsum, the degradation of the damaged part is caused by the formation of expansive gypsum and incohesive $\mathrm{M}-\mathrm{S}-\mathrm{H}$. The wet-dry alternated and immersion tests indicate that not only the degradation rate of the wet-dry alternated test is much faster than immersion test but also its degradation process is more similar to the corroded sidewall.

(3) For an in-service structure exposed to sulfate environment, degradation depth is best suited for evaluating the damage degree and calculating the residual life. Since the specimens in the laboratory are smaller than the field structure, the corrosion degree that makes the in-service structure unstable is very difficult to be achieved in the laboratory test.

To solve this problem, in this paper, based on a modified theoretical model, combining with the limit data form the wet-dry alternated tests and field investigations, the remaining service life of the shaft sidewall is estimated. The results indicate that the service life of the auxiliary shaft of Lin-Huan coal mine is 51 years, and there is no need to reinforce in the next 25 years.

\section{Data Availability}

The data used to support the findings of this study are available from the corresponding author upon request.

\section{Conflicts of Interest}

The authors declare that there are no conflicts of interest regarding the publication of this paper.

\section{Acknowledgments}

The authors gratefully acknowledge the financial support provided by the Beijing Municipal Education Commission Science and Technology General Project (no. KY201712448004) and the Huaibei Ming Group Co. Ltd.

\section{References}

[1] A. Leemann and R. Loser, "Analysis of concrete in a vertical ventilation shaft exposed to sulfate-containing groundwater for 45 years," Cement and Concrete Composites, vol. 33, no. 1, pp. 74-83, 2011.

[2] J. H. Liu, L. B. Bian, W. He, W. J. Zhou, and C. W. Han, "Investigation and destruction mechanism on corrosion of concrete shaft in coal mine," Journal of China Coal Society, vol. 40, no. 3, pp. 528-533, 2015.

[3] J. R. Clifton and L. I. Knab, NUREG/CR-5466: Service Life of Concrete, Nuclear Regulatory Commission, Washington, DC, USA, 1989.

[4] L. W. Masters, Problems in Service Life Prediction of Building and Construction Materials, Springer, Berlin, Germany, 1985.
[5] J. R. Clifton and D. J. Naus, ACI 365.1R-00: Service-Life Prediction-State of the Art Report, American Concrete Institute Committee, Farmington Hills, MI, USA, 2000.

[6] J. C. Walton, L. E. Plansky, and R. W. Smith, NUREG/CR5542: Models for Estimation of Service Life of Concrete Barriers in Low-Level Radioactive Waste Disposal, Nuclear Regulatory Commission, Washington, DC, USA, 1990.

[7] A. Atkinson and J. A. Hearne, "Mechanistic model for the durability of concrete barriers exposed to sulphate-bearing groundwaters," MRS Proceedings, vol. 176, pp. 149-159, 1989.

[8] E. Vesikari, Service Life Design of Concrete Structures with regard to the Frost Resistance of Concrete, Publication No. 5, Nordic Concrete Research, Norske Betongforening, Oslo, Norway, 1986.

[9] U. Schneider and S. W. Chen, "Modeling and empirical formulas for chemical corrosion and stress corrosion of cementitious materials," Materials and Structures, vol. 31, no. 10, pp. 662-668, 1998.

[10] G. L. Kalousek, L. C. Porter, and E. J. Benton, "Concrete for long-time service in sulfate environment," Cement and Concrete Research, vol. 2, no. 1, pp. 79-89, 1972.

[11] Y. G. Guan, W. Sun, and C. W. Liao, "One service-life prediction model for the concrete based on the reliability and damage theories II: narration and establishment of the model," Journal of the Chinese Ceramic Society, vol. 29, no. 6, pp. 530-534, 2001.

[12] MOHURD (Ministry of Housing and Urban-Rural Development of the People's Republic of China), GB50021-2001: Code for Investigation of Geotechnical Engineering, MOHURD, Beijing, China, 2009.

[13] F. Bellmann, B. Möser, and J. Stark, "Influence of sulfate solution concentration on the formation of gypsum in sulfate resistance test specimen," Cement and Concrete Research, vol. 36, no. 2, pp. 358-363, 2006.

[14] I. Biczok, Concrete Corrosion and Concrete Protection, Chemical Publishing Company, Palm Springs, CA, USA, 1967.

[15] O. S. B. Al-Amoudi, "An Attack on plain and blended cements exposed to aggressive sulfate environments," Cement and Concrete Composites, vol. 24, no. 3-4, pp. 305-316, 2002.

[16] S. L. Xu and G. F. Zhao, "Double-K fracture criterion for the crack propagation in concrete structures," China Civil Engineering Journal, vol. 1992, no. 2, pp. 32-38, 1992.

[17] CEC (China Electricity Council), DL/T 5332-2005: Norm for Fracture Test of Hydraulic Concrete, China Electricity Council, Beijing, China, 2005.

[18] S. Kumar and S. V. Barai, "Size-effect prediction from the double-K fracture model for notched concrete beam," International Journal of Damage Mechanics, vol. 19, no. 4, pp. 473-497, 2010.

[19] W. D. Li, Nondestructive Testing Technology for Concrete, Tongji University Press, Shanghai, China, 1989.

[20] G. Frohnsdorff, L. W. Masters, and J. W. Martin, NBS Technical Note 1120: An Approach to Improved Durability Tests for Building Materials and Components, National Bureau of Standards, Gaithersburg, MD, USA, 1980.

[21] M. Maali, H. Showkati, and S. M. Fatemi, "Investigation of the buckling behavior of conical shells under weld-induced imperfections," Thin-Walled Structures, vol. 57, no. 6, pp. 13-24, 2012.

[22] H. Xf, W. T. Liu, and H. Y. Yang, "Acceleration corrosion factor for aluminum alloys: model and analysis," Journal of Aeronautical Materials, vol. 28, no. 3, pp. 77-81, 2008. 
[23] E. Vesikari, Service Life Design of Concrete Structures with Regard to the Frost Resistance of Concrete, Nordic Concrete Research Norway, Norske Betongforening, Oslo, Norway, 1986.

[24] G. L. Kalousek, L. C. Porter, and E. J. Benton, "Concrete for long-time service in sulfate environment," Cement and Concrete Research, vol. 2, no. 1, pp. 79-89, 1972.

[25] S. W. Li, Y. F. Wang, and S. N. Wang, "Research on the prediction model of the concrete damage in the sulfate aggressive environment," Journal of Wuhan University of Technology, vol. 2010, no. 14, pp. 35-39, 2010.

[26] Y. Zhou, H. Tian, H. Cui et al., "Model for sulfate diffusion depth in concrete under complex aggressive environments and its experimental verification," Advances in Materials Science and Engineering, vol. 2015, Article ID 693834, 11 pages, 2015.

[27] W. H. Yang and H. L. Fu, "Theoretical investigation on vertical additional force on shaft lining in special stratum," International Journal of Mining Science and Technology, vol. 1999, no. 2, pp. 129-135, 1999.

[28] J. P. Li, Rock Mechanics in Mine, Metallurgical Industry Press, Beijing, China, 2011.

[29] J. M. Ni, "Classification of surrounding rock stability of coal roadway in Huaibei mining area and research on support measures," M.S. dissertation, China University of Ming and Technology, Beijing, China, 2008.

[30] P. Zhang, "Deep mine roadway in Lin-huan coal mine of Huai-bei top floor deformation," M.S. dissertation, Hu'nan University of Science and Technology, Xiangtan, China, 2014.

[31] J. J. Yang, "Failure and strength characteristics of the concrete shaft ling," Journal of China Coal Society, vol. 1998, no. 3, pp. 246-251, 1998.

[32] J. J. Yang and W. R. Sun, "On strength and design of reinforced concrete shafting," Journal of Anhui University of Science and Technology, vol. 1994, no. 3, pp. 23-27, 1994.

[33] H. Cheng, Y. F. Yao, C. X. Rong, and H. B. Cai, "Fuzzy random reliability analysis on outer shaft lining in the process of freezing method sinking for deep alluvium," Journal of the China Coal Society, vol. 42, no. 5, pp. 1099-1107, 2017.

[34] J. Xiao, W. J. Qu, P. Zhu, and Y. P. Zhu, "Stochastic process model of sulfuric acid-caused corrosion depth of concrete," Journal of South China University of Technology, vol. 44, no. 7, pp. 108-115, 2016.

[35] Z. Li, Research on reliability analysis and design of bearing capacity of composite foundation, Ph.D. dissertation, Xi'an University of Architecture and Technology, Xi'an, China, 2008.

[36] MOHURD (Ministry of Housing and Urban-Rural Development of the People's Republic of China), GB 50068-2001: Unified Standard for Reliability Design of Building Structures, MOHURD, Beijing, China, 2001. 


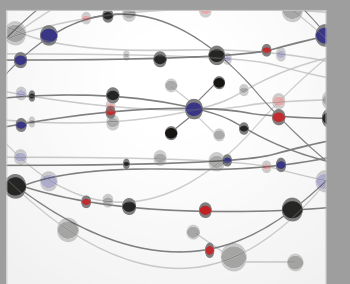

The Scientific World Journal
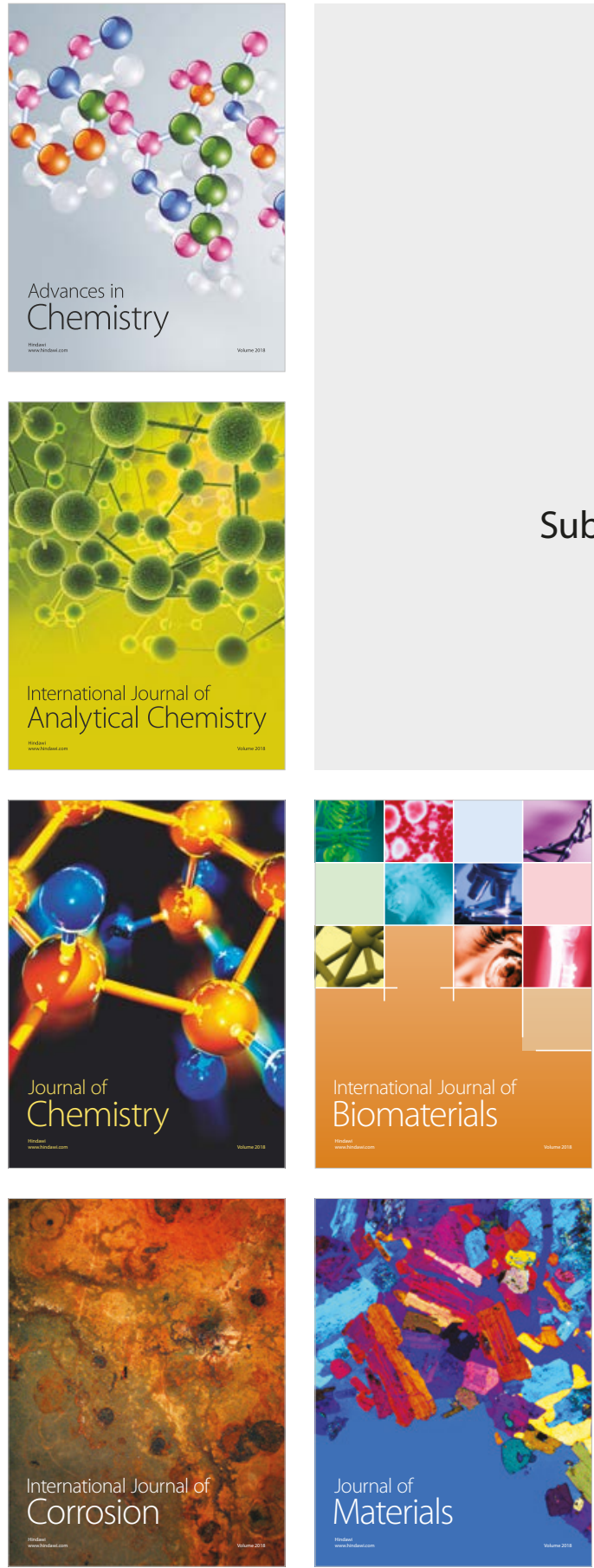

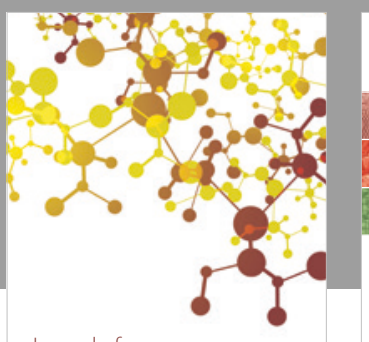

Journal of

Applied Chemistry
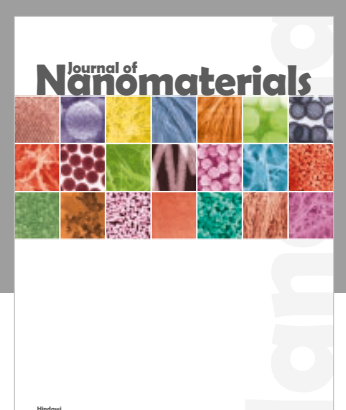

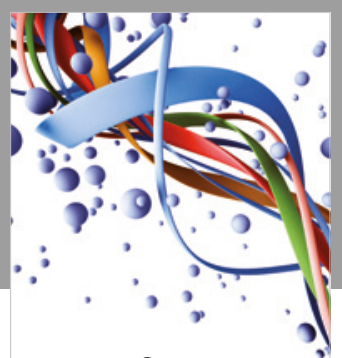

Scientifica

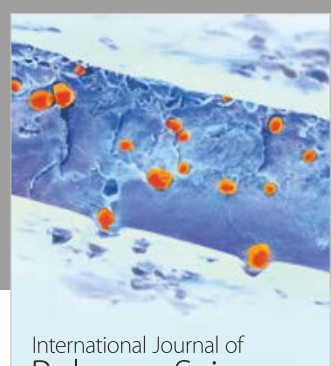

Polymer Science

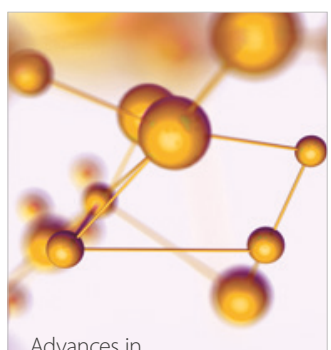

Physical Chemistry
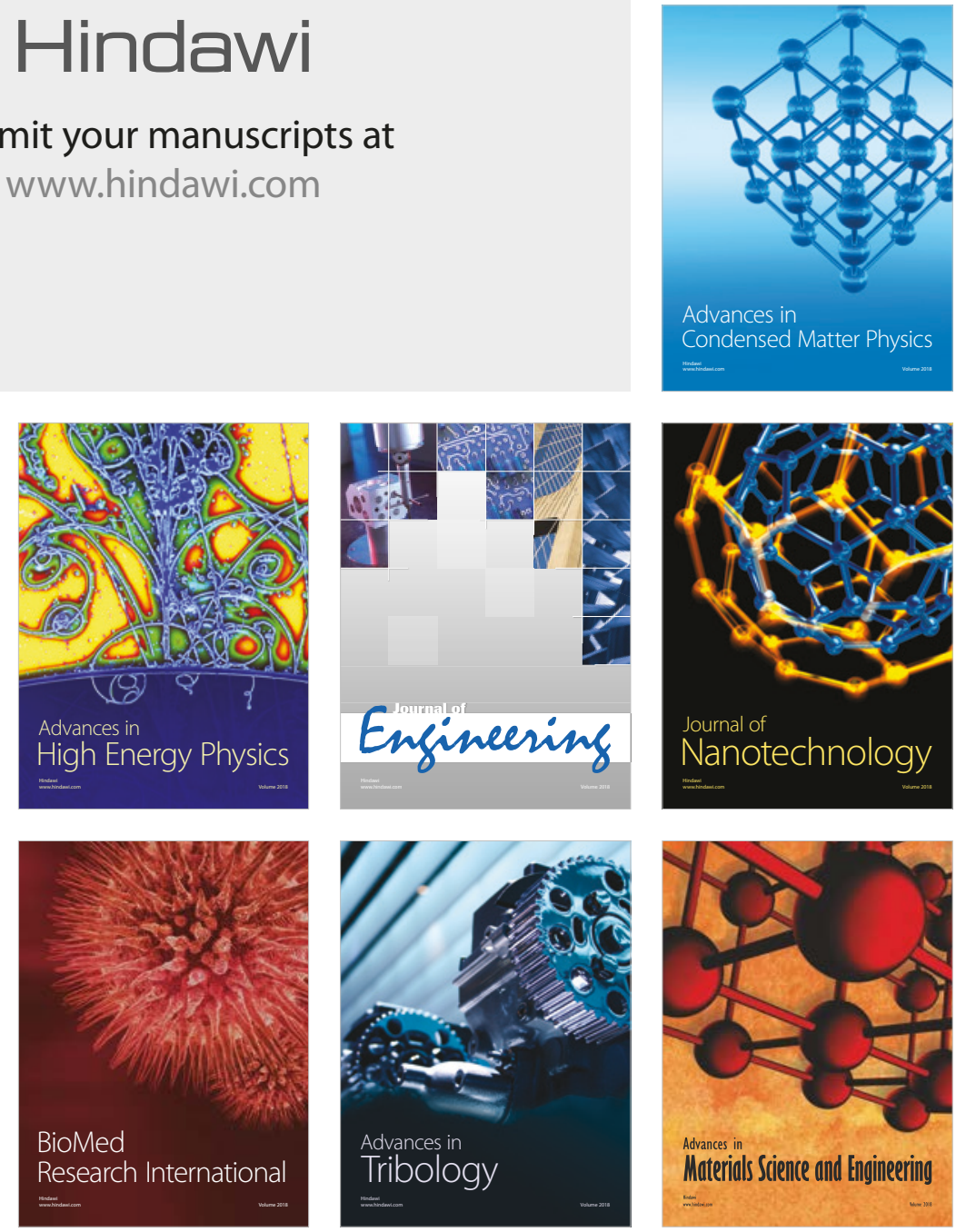